\title{
Androgens impair $\beta$-cell function in a mouse model of polycystic ovary syndrome by activating endoplasmic reticulum stress
}

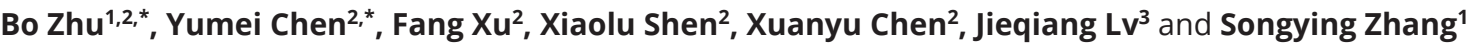 \\ 1'Department of Obstetrics and Gynecology, Assisted Reproduction Unit, Sir Run Run ShawHospital, Zhejiang University School of Medicine Key \\ Laboratory of Reproductive Dysfunction Management of Zhejiang Province, Hangzhou, Zhejiang, China \\ 2Department of Gynecology and Obstetrics, Wenzhou People's Hospital, Wenzhou Women and Children Health, Wenzhou, Zhejiang, China \\ ${ }^{3}$ Department of Gynecology and Obstetrics, the Second Affiliated Hospital of Wenzhou Medical University, Wenzhou, Zhejiang, China \\ Correspondence should be addressed to J Lv or S Zhang: jieqianglu@126.com or zhangsongying@zju.edu.cn
}

*(B Zhu and Y Chen contributed equally to this work)

\begin{abstract}
Background: Androgens excess results in endoplasmic reticulum (ER) stress, which is an important cause of $\beta$ cells dysfunction. Here, we investigated the molecular regulation of androgens excess, ER stress, and $\beta$-cell function in polycystic ovary syndrome (PCOS). Methods: PCOS mouse model was established by injection of DHEA. Primary cultured mouse islets were used to detect testosterone (TE)-induced ER stress. The response of ER stress, apoptosis, and hyperinsulinemia were analyzed in INS-1 cells with or without TE exposure. Androgen receptor (AR) antagonist and ER stress inhibitor treatment was performed to evaluate the role of TE in ER stress and proinsulin secretion of PCOS mice. Results: PCOS mice had higher ER stress in islets. TE exposure induced ER stress and apoptosis significantly through sustaining insulin overexpression in $\beta$ cells, which in turn impaired proinsulin maturation and secretion. Blocking this process could significantly relieve ER stress and apoptosis and improve insulin homeostasis.

Conclusion: ER stress activated by androgens excess in PCOS contributes to $\beta$ cell dysfunction and hyperinsulinemia.
\end{abstract}
Key Words
- ER stress
- androgens excess
- $\beta$ cells
- hyperinsulinemia
- PCOS

\section{Introduction}

Polycystic ovary syndrome (PCOS), one of the most common endocrine and metabolic disorders, affects $5-20 \%$ of women of reproductive age, is characterized by hyperandrogenism, ovulatory dysfunction, and polycystic ovarian morphology $(1,2)$. Women with PCOS have increased risk for type 2 diabetes (T2DM), obesity, infertility, obstetrical complications, mood disorders, and endometrial cancer, which may also increase the risk of cardiovascular diseases, venous thromboembolism, and ovarian cancer $(3,4)$. In 2018, the economic losses caused by PCOS was more than 4 billion dollars in the United States, even without considering the cost of the increased risk of obstetrical complications $(3,5,6)$.
Although the etiology of PCOS is complex and unclear, recent studies reveal that androgens excess and endoplasmic reticulum (ER) stress play important roles in the progression and pathogenesis of PCOS (7, $8,9)$. Clinical studies showed that hyperandrogenism is found in most of women who suffer from PCOS, which indicates androgens excess have a causative role in PCOS (10). Female patients with congenital adrenal hyperplasia that have higher endogenous adrenal androgen levels, are reported to present PCOS morphological features (11). Androgen functions are mediated through the androgen receptor (AR) that have been strongly linked to the development of PCOS. Flutamide (Flut) is an AR antagonist

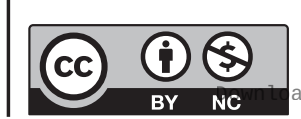

This work is licensed under a Creative Commons Attribution-NonCommercial 4.0 International License. ded from Bioscientifica.com at 04/26/2023 06:10:04AM 
that can restore the impaired menstrual regularity and ovulation in some PCOS patients and repair reproductive and metabolic disorders in PCOS models $(12,13,14)$. Moreover, knockdown of AR can inhibit the metabolic and reproductive traits of PCOS in mouse model (15).

ER stress promotes the accumulation of unfolded or misfolded proteins caused by numerous pathological and physiological conditions, such as inflammation and oxidative stress (16). ER stress activates various signal transduction cascades generally termed as the unfolded protein response (UPR) that reprogram gene transcription/ translation and protein translation/modification, relieve the load of misfolded or unfolded proteins, and restore homeostasis of cellular proteins (17). In PCOS patients and mice, the androgen activates ER stress in granulosa cells, which inhibit the development and growth of antral follicles and result in ovarian fibrosis $(1,18)$. Recently, Takahashi et al. reported that ER stress is stimulated in granulosa cells of patients with PCOS and mouse model, which induces the expression of pro-fibrotic growth factors, such as transforming growth factor (TGF- $\beta$ ), fibroblast growth factor (FGF), and platelet-derived growth factor (PDGF), during ovarian fibrosis (18).

Pancreatic $\beta$ cells have a large amount of ER that reflects their physiological function as proinsulin maturation and insulin secretion, and disruption of ER homeostasis in $\beta$ cells affect their physiological function and result in excessive amount of insulin in circulation, hyperinsulinemia, which in turn may aggravate the ES stress of $\beta$ cells $(19,20,21)$. However, the relationships among androgens excess, hyperinsulinemia, and ER stress in $\beta$ cells of PCOS is still unclear. To address this question, we first detected the ER stress status in islets of the well-established dehydroepiandrosterone (DHEA)induced PCOS animal model and revealed the effects of testosterone (TE) on ER stress and apoptosis in both INS-1 cells and primary cultured mouse islets. Finally, we demonstrated that TE induced ER stress by sustained insulin overexpression in vitro and in vivo through performing AR antagonist (Flut) and ER stress inhibitor (TUDCA) administrations.

\section{Materials and methods}

\section{Animal model and treatment}

28-day old C57BL/6J female mice were purchased from Wenzhou medical University and divided into three groups: control, dehydroepiandrosterone (DHEA)-induced
PCOS, and DHEA+flutamide (Flut, an AR antagonist). PCOS mouse model was created by the administration of DHEA as described previously $(22,23)$. Briefly, control mice were subcutaneously injected with sesame oil and, and implanted subcutaneously with an empty pellet; PCOS mice were subcutaneously injected with DHEA (Sigma-Aldrich) and implanted subcutaneously with an empty pellet; DHEA+Flut mice were subcutaneously injected with sesame oil and implanted subcutaneously with a pellet containing $20 \mathrm{mg}$ flutamide (Innovative Research of America, Sarasota, FL, USA). The treatment was continued daily for 20 consecutive days. Each group had 10-12 mice. The study was approved by the ethics commitment of Assisted Reproduction Unit, Sir Run Run Shaw Hospital, Zhejiang University School of Medicine.

\section{Islet isolation and culture}

The islets were isolated from the female mice as previously described $(24,25)$. C57BL/6J female mice were anesthetized by intraperitoneal injecting $100 \mathrm{mg} / \mathrm{kg}$ pentobarbital (Nembutal, Abbott Laboratories). Then their pancreatic gland was isolated and digested by collagenase. Pancreatic islets were then separated from the digest by density gradient centrifugation using Histopaque 1077. Microdissected, and hand-picking were conducted under a stereomicroscope to ensure high purity.

\section{Cell culture and treatment}

Isolated islets and INS-1 cells were cultured in the RPMI 1640 medium (Thermo Fisher Scientific Inc.), which contained 10\% PBS, $11.1 \mathrm{mM}$ glucose, $100 \mu \mathrm{g} / \mathrm{mL}$ streptomycin, and $100 \mathrm{U} / \mathrm{mL}$ penicillin, and placed at $37^{\circ} \mathrm{C}$ in $5 \% \mathrm{CO}_{2}$ incubator. Culture medium was changed every 2 days. Five groups of treatment: Control, no treatment; Cytokine cocktail (CC, 10 ng/mL IL-1 $\beta, 100$ ng/mL IFN- $\gamma$, and $25 \mathrm{ng} / \mathrm{mL}$ TNF- $\alpha$ ) treatment as positive control of ER dysfunction; and three TE treatments with the concentration of $0.01,0.1$ and $1 \mu \mathrm{g} / \mathrm{mL}$. The islets and INS-1 cells were treated under the above conditions for $72 \mathrm{~h}$, and then were harvested for gene expression analysis.

\section{Real-time quantitative reverse transcription PCR (qRT-PCR)}

Total RNA of islets and INS-1 cells was extracted by using the TRIzolTM Reagent (Invitrogen), according to the manufacturer's instructions. Total RNA and M-MLV Reverse Transcriptase (Beyotime, Shanghai, China)

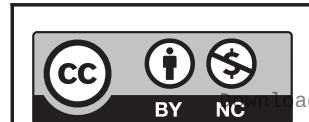

This work is licensed under a Creative Commons Attribution-NonCommercial 4.0 International License. ded from Bioscientifica.com at 04/26/2023 06:10:04AM via free access 
were used to synthesize the cDNA. The qRT-PCR was conducted using Bio-Rad MyIQ IQ1 single-color real-time PCR detection system (Bio-Rad Laboratories, Inc.). The expression of target genes was normalized by GAPDH and calculated by using $2^{-\Delta \Delta \mathrm{CT}}$ method. The primers were $\left(5^{\prime}-3^{\prime}\right)$ :

\section{Perk}

Forward: CGCGTCGGAGACAGTGTTT

Reverse: GTCCTCCACGGTCACTTCG

Atf6

Forward: TCGCCTTTTAGTCCGGTTCTT

Reverse: GGCTCCATAGGTCTGACTCC

Ire1

Forward: ATGGCGAGACCAGTCCAGA

Reverse: TCCGTCCAAGGTAGACACAAA

\section{Xbp1(s)}

Forward: AGCTTTTACGGGAGAAAACTCAC

Reverse: CCTCTGGAACCTCGTCAGGA

\section{Chop}

Forward: AAGCCTGGTATGAGGATCTGC

Reverse: TTCCTGGGGATGAGATATAGGTG

\section{DR5}

Forward: CGGGCAGATCACTACACCC

Reverse: AGTTCCCTTCTGACAGGTACTG

\section{Gapdh}

Forward: AGGTCGGTGTGAACGGATTTG

Reverse: GGGGTCGTTGATGGCAACA

\section{Apoptosis assay}

The apoptotic status of the INS-1 cells under different treatments (control, CC, TE $(0.1 \mu \mathrm{g} / \mathrm{mL})$, TE+Flut $(5 \mu \mathrm{M})$, and TE+TUDAC $(100 \mu \mathrm{M}$, an ER stress inhibitor) $)$ were detected by using Annexin V/PI staining (Thermo Fisher Scientific Inc.), followed with flow cytometry analysis.

\section{Western blot}

The treated INS-1 cells or islets were lysed using the medium RIPA lysis buffer (Beyotime) with fresh protease inhibitor cocktail (Promega). Target proteins expression was determined by Western blot as previous described (26). Primary antibodies of Bcl-2 (1:1000 dilution), Bax (1:1000 dilution), GAPDH (1:2000 dilution), and cleaved caspase3 (1:1000 dilution) were ordered from CST (Danvers, U.S.); Proinsulin MAB (D3E7) and insulin MAB (ICBTACLS) were obtained from Thermo Fisher Scientific Inc.

\section{ELISA}

The INS- 1 cells were treated by PBS control and TE for $24 \mathrm{~h}$, then harvested the conditional medium at 24-, 36-, 48-, 60-, and 72-h for the proinsulin and insulin measurement. The concentration of proinsulin and insulin was determined by using ELISA kit (ALPCO, Salem, USA) following the manufacturer's instructions.

\section{Statistical analysis}

Statistical analyses were performed by using the GraphPad Prism (https://www.graphpad.com/). One or two-way ANOVA and Student's $t$-test methods were used to analyze the differences between groups. The data were represented as mean \pm S.D., ${ }^{*} P<0.05,{ }^{* *} P<0.01$, and ${ }^{* * *} P<0.001$ compared to control group; ${ }^{\# \#} P<0.01$, and ${ }^{\# \# \# P}<0.001$ compared to TE treated group.

\section{Results}

\section{ER stress is elevated in the islets of PCOS mice}

In order to evaluate the ER stress status in PCOS mice, created by the administration of DHEA, islets of controls and mice with PCOS were isolated for gene expression analysis by qRT-PCR. First, we examined protein kinase RNA-like ER kinase (PERK), activating transcription factor-6 (ATF6), and inositol-requiring enzyme-1 (IRE1), the key regulators of UPR pathway, and found all of them were upregulated in PCOS mice compared to those in controls (Fig. 1). XBP1 is the downstream regulator of UPR, which was also significantly increased in PCOS mice (Fig. 1). The sustaining ER stress will activate the apoptosis signaling pathway, which is mainly mediated by UPR transcription factor C/EBP homologous protein (CHOP) and death receptor (DR) (27). Interestingly, both CHOP and DR5 were also significantly increased in PCOS

This work is licensed under a Creative Commons Attribution-NonCommercial 4.0 International License. ded from Bioscientifica.com at 04/26/2023 06:10:04AM via free access 


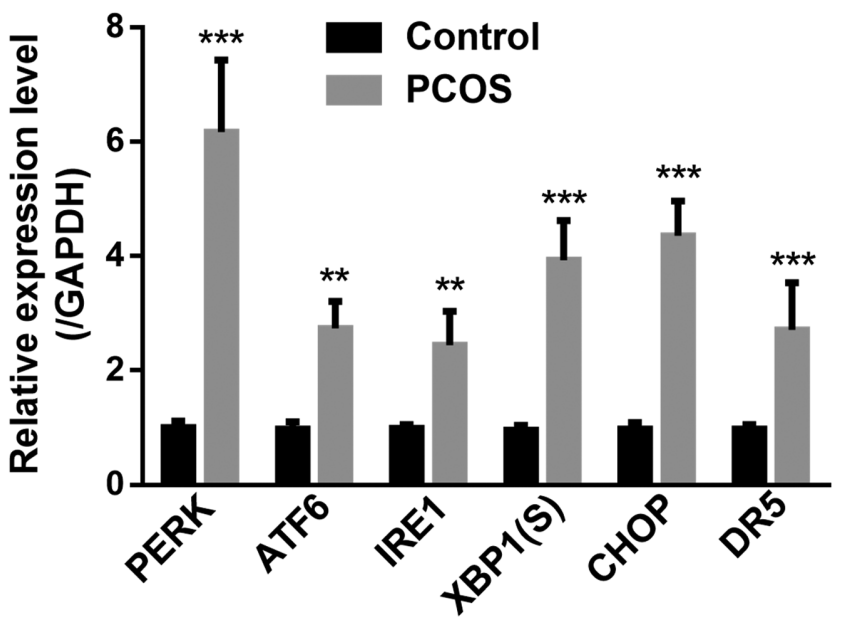

Figure 1

Expression of UPR-related genes in islets of control and mice with PCOS. Levels of PERK, ATF6, IRE1, XBP1(S), CHOP and DR5 mRNA in islets of controls and mice with PCOS ( $n=12$ for each group) were measured by real-time $P C R$ and normalized against GAPDH. UPR, unfolded protein response. XBP1(S), spliced XBR1. CHOP, UPR transcription factor C/EBP homologous protein. DR5, Death receptor5. Values represent means \pm S.D. $\star \star P P 0.01, * \star \star P P 0.001$ compared with control.

mice relative to those in controls (Fig. 1). These results suggested that the obvious ER stress and apoptosis were underway in the islets of PCOS mice.

\section{Testosterone induces ER stress in INS-1 cells}

Hyperandrogenism is the most consistent feature observed in PCOS patients, therefore, we investigated the ER stress status of $\beta$ cells after the TE administration by qRT-PCR. The cytokine cocktail (50 ng/mL IL- $1 \beta$, $100 \mathrm{ng} / \mathrm{mL}$ IFN- $\gamma$, and $25 \mathrm{ng} / \mathrm{mL}$ TNF- $\alpha$ ) was used as the positive control that induced the expression of all three ER stress markers XBP1(S), CHOP, and DR5 in INS-1 cells (Fig. 2A). Three constrictions of TE were set up, 0.01, 0.1 , and $1 \mu \mathrm{g} / \mathrm{mL}$, and the results showed that ER stress markers were significantly upregulated along with the consistence increase and presented a dose-dependent pattern (Fig. 2A). Similar trend was observed in primary cultured mouse islets (Fig. 2B). The above data indicated that testosterone induced the ER stress status in $\beta$ cells.

\section{Testosterone increases apoptosis of INS-1 cells}

The UPR-induced apoptosis pathway was significantly increased in islets of PCOS mice (Fig. 1), next, we investigated the regulatory role of TE on apoptosis of $\beta$ cells in vitro. Similar to the CC positive control, TE $(0.1 \mu \mathrm{g} / \mathrm{mL})$ administration induced apoptosis of INS-1 cells detected by Hoechst 33342 staining significantly (Fig. 3A and B). Moreover, the protein level of apoptotic markers, cleaved caspase 3 and Bax, was significantly upregulated after TE administration, accordingly, protein level of Bcl-2 was downregulated with TE treatment (Fig. $3 \mathrm{C}$ and D). To further examine the TE-induced apoptosis in INS-1 cells, we performed TE+Flut (an AR antagonist) and TE+TUDAC (an ER stress inhibitor) to block the AR and ER stress processes in INS-1 cells. The results showed that blocking AR signaling pathway significantly reduced the TE-induced apoptosis on Hoechst 33342 staining (Fig. 3A and B) and apoptotic markers (Fig. 3C and D) levels, strikingly, the inhibitory effect of Flut (AR antagonist) and TUDAC (ER stress inhibitor) were comparable (Fig. $3 \mathrm{~A}, \mathrm{~B}, \mathrm{C}$ and D). These results suggested that TE increased apoptosis of $\beta$ cells which could be reduced by the inhibition of AR signaling and ER stress.

\section{Testosterone induces ER stress by sustained insulin overexpression}

Chronic androgens excess results in hyperinsulinemia and insulin resistance, which in turn injury the function of $\beta$ cells $(28,29)$. Next, we examined the proinsulin and insulin levels in conditional medium of INS-1 cells after TE administration using ELISA. As shown in Fig. 4A and $\mathrm{B}$, the concentration of both proinsulin and insulin in conditional medium was significantly increased along

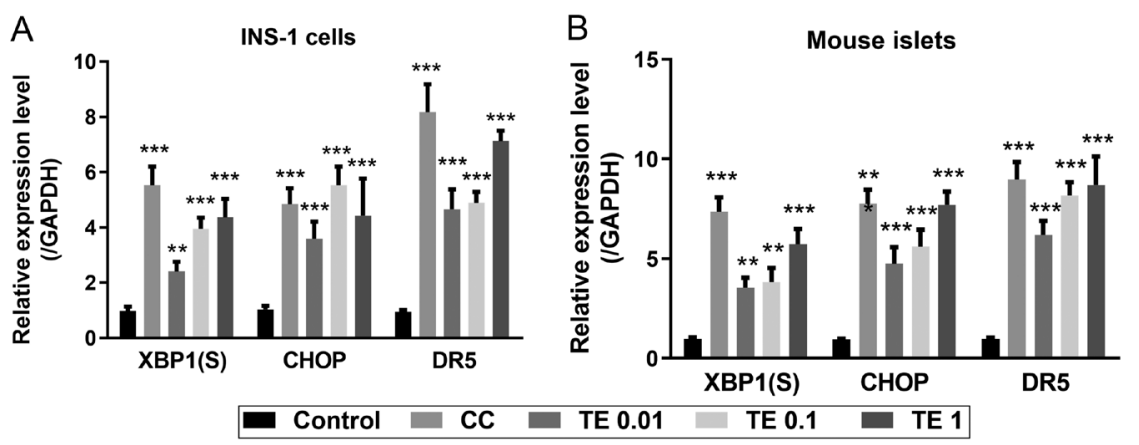

Figure 2

TE-induced ER stress in INS-1 cells and primary cultured mouse islets. Levels of XBP1(S), CHOP and DR5 mRNA in INS-1 cells (A) and primary cultured mouse islets (B) were measured by real-time PCR and normalized against GAPDH. XBP1(S), spliced XBR1. CHOP, UPR transcription factor C/EBP homologous protein. DR5, death receptor5; CC, cytokine cocktail; TE, Testosterone. Values represent means \pm S.D. $* * P<0.01$, $\star \star \star P<0.001$ compared with control.

https://ec.bioscientifica.com https://doi.org/10.1530/EC-20-0608 (c) 2021 The authors Published by Bioscientifica Ltd

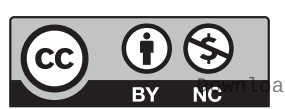

This work is licensed under a Creative Commons Attribution-NonCommercial 4.0 International License. ded from Bioscientifica.com at 04/26/2023 06:10:04AM via free access 
A
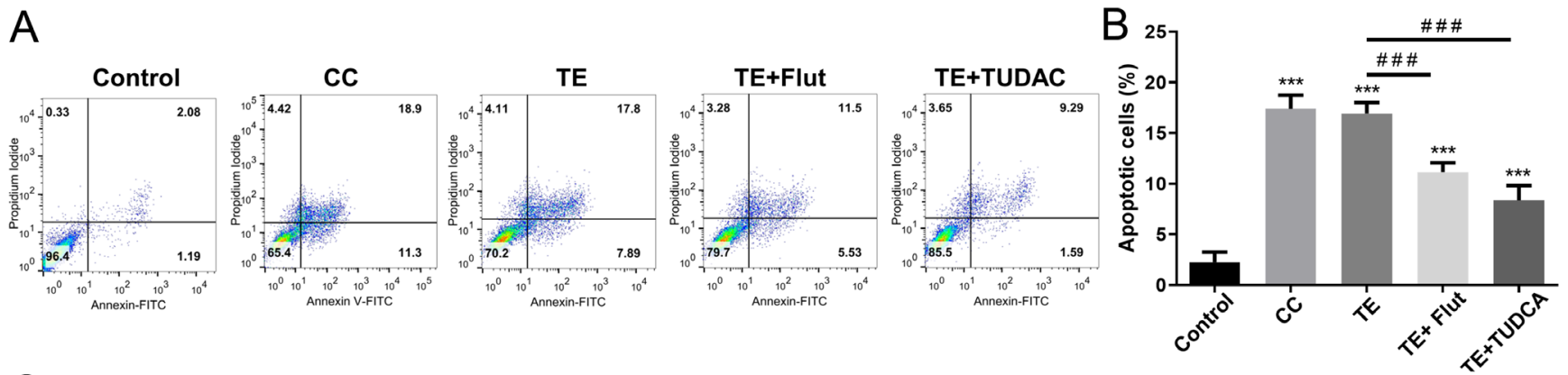

C

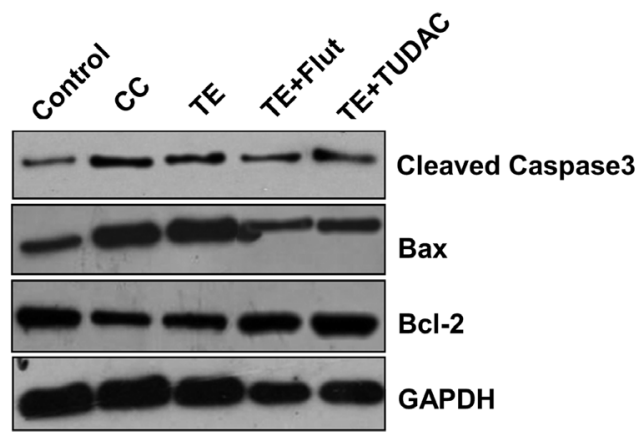

D

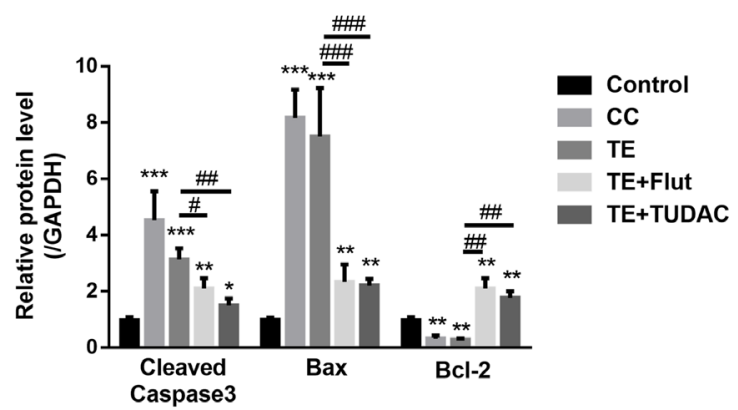

Figure 3

Inhibition of ER stress ameliorates TE-induced apoptosis in INS-1 cells. (A and B) Cell was treated as described in the 'Materials and methods' section. The apoptosis rate was detected by Annexin V/PI staining. (C) Expression of cleaved caspase-3, Bax and Bcl-2 were detected by Western blot analysis. Values represent means \pm S.D. ${ }^{* *} P<0.01,{ }^{*} * * P<0.001$ compared with control. $\# P<0.05,{ }^{\#} P<0.01, \# \# P<0.001$.

with the TE treatment times. Western blot analyses of proinsulin and insulin showed the same trend (Fig. 4C). However, INS-1 cells were treated by the combination $\mathrm{TE}$ and Cyclo (an inhibitor of protein synthesis), which blocked the production of insulin, could decrease the expression of ER stress markers significantly (Fig. 4D). The above data indicated that TE-induced ER stress was sustained by insulin overexpression in $\beta$ cells.

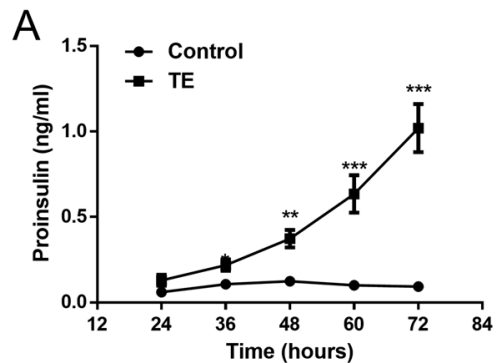

C

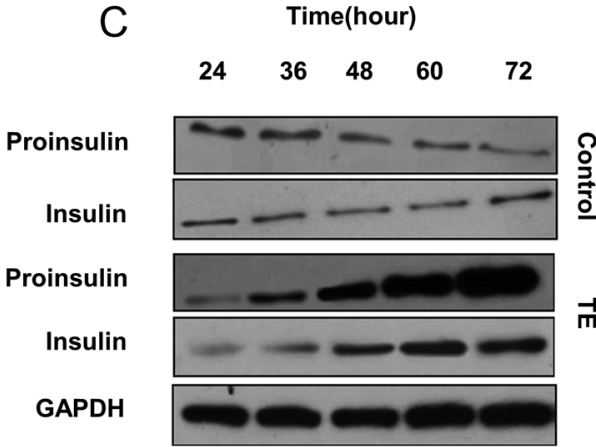

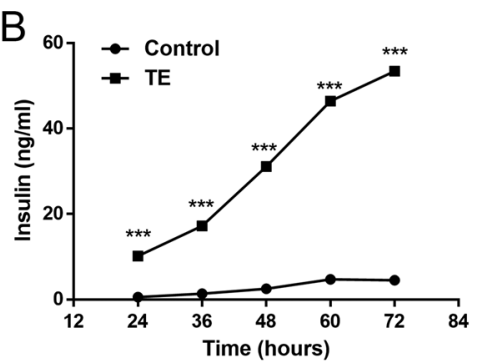

D

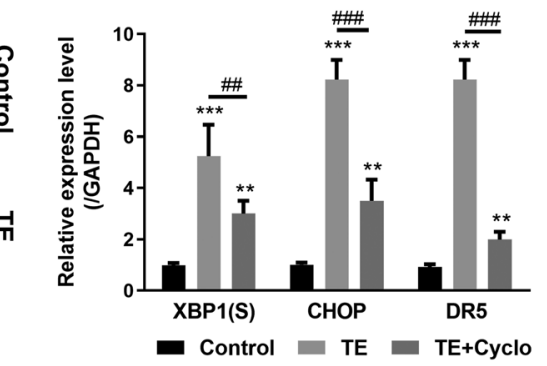

\section{Figure 4}

TE-induced ER stress by sustained insulin overexpression. (A and B) INS-1 cells were treated with $0.1 \mu \mathrm{g} / \mathrm{mL} \mathrm{TE}$, and culture media were collected to measure proinsulin (A) and insulin (B) content by ELISA at each time point. (C) Cells were harvested, and proinsulin, insulin were tested by Western blot. (D) INS-1 cells were treated with $0.1 \mu \mathrm{g} / \mathrm{mL}$ TE without or with Cyclo (cycloheximide $0.1 \mu \mathrm{mol} / \mathrm{L}$ ). Levels of XBP1(S), CHOP and DR5 mRNA in INS-1 cells were measured by real-time PCR and normalized against GAPDH. Values represent means \pm S.D. $\star * P<0.01, * * * P<0.001$ compared with control. $\# \#<0.01, \# \# P<0.001$. https://ec.bioscientifica.com https://doi.org/10.1530/EC-20-0608 (c) 2021 The authors Published by Bioscientifica Ltd

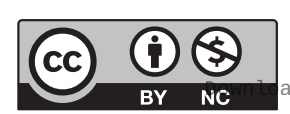

This work is licensed under a Creative Commons Attribution-NonCommercial 4.0 International License. ded from Bioscientifica.com at 04/26/2023 06:10:04AM 


\section{Insulin secretion and proinsulin maturation are} impaired in islets of PCOS mice

Next, we investigated the serum proinsulin and insulin levels in controls, PCOS, and PCOS plus Flut treatment mice. As shown in Fig. 5A, DHEA-induced PCOS mice had higher serum insulin level, which could be reduced by Flut treatment. A similar phenomenon was also happened for proinsulin (data not shown). Similarly, the proinsulin/ insulin ratio was significantly elevated in PCOS mice, and restored to a lower level after Flut treatment (Fig. 5B). Moreover, Western blot of proinsulin and insulin presented the same trend that AR antagonist could partially restore the impaired insulin secretion and proinsulin maturation (Fig. 5C and D), which further suggested that androgenregulated ES stress and $\beta$ cell function in islets.

\section{Discussion}

ER stress and correspondingly apoptosis are important causes of the dysfunction of islet $\beta$ cells (29). As one of the major features of PCOS, ER stress can be induced by androgens excess (1). Meanwhile, androgens excess also result in hyperinsulinemia in female mice (28). However, the relationships among androgens excess, hyperinsulinemia, and ER stress in $\beta$ cells of PCOS is unclear. XBP1 haploinsufficiency mice succumb to ER stress and develop hyperinsulinemia, and impaired insulin and glucose tolerance relative to WT mice (30). In hyperinsulinemic status, misfolded proinsulin accumulates in the ER of pancreatic $\beta$ cells, which results in the activation of UPR signaling and then leads to $\beta$ cell apoptosis. In addition, ER stress also correlates with inflammation in pancreatic $\beta$ cells, therefore strategies targeting cytokines such as IL-22 and IL-24 could ameliorate insulin secretion and insulin resistance through suppressing ER stress and inflammation (31). The current study showed the significantly increased ER stress status in islets of PCOS mouse, which could be induced by TE exposure. In addition, TE treatment also resulted in apoptosis of $\beta$ cells significantly. Mechanistically, TE induces ER stress and apoptosis of $\beta$ cells through sustaining insulin overexpression, which in turn impair proinsulin maturation and insulin secretion, and finally aggravate the development and progression PCOS. Importantly, blocking this process by using AR antagonist (Flut) or ER stress inhibitor (TUDAC) could significantly relieve ER stress and apoptosis, and improve insulin homeostasis.

The ER stress is involved in the development of insulin resistance and hyperinsulinemia (31). Nonesterified fatty acids (NEFAs) derived from visceral adipose tissue in obese patients are able to induce ER stress and elevate the expression of cytokines such as IL- 6 and TNF- $\alpha$ through UPR signaling pathway, which induces positive ER stress feedback, inhibit insulin action, and result in hyperinsulinemia $(32,33,34)$. In this study, we found that TE possessed a similar promoting effect on proinsulin and insulin expression, notably, there was more significant increase of proinsulin level than insulin in the TE treated mice (higher proinsulin:insulin ratio), which indicates that more unfolded and modified insulin are secreted into
A

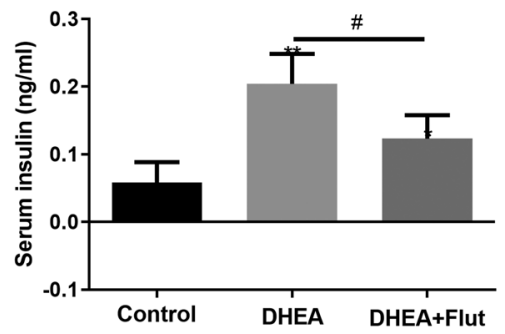

C

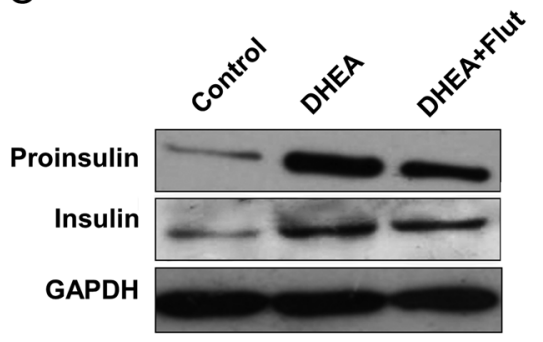

B

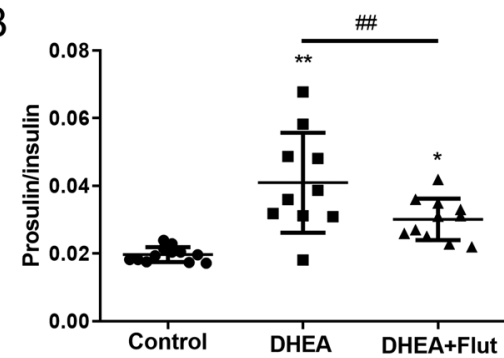

$\mathrm{D}$

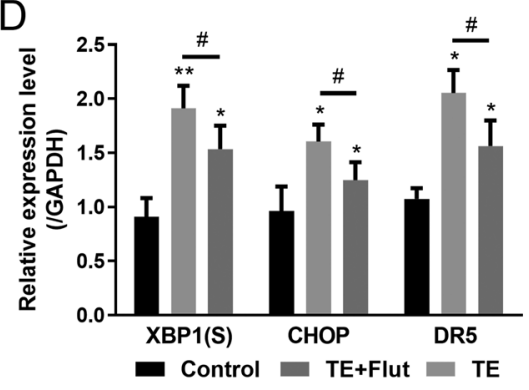

Figure 5

Administration of AR antagonist ameliorates ER stress in PCOS mice. Serum insulin levels $(A)$ and proinsulin levels relative to total insulin (B) in mice of different groups were determined by ELISA. $n=10-12$ mice in each group. (C) Insulin and proinsulin levels in islets of mice from different groups were determined by Western blot. $n=6-8$ mice in each group. (D) Levels of XBP1(S), CHOP and DR5 mRNA in islets of mice from different groups were measured by real-time PCR and normalized against GAPDH. DHEA, dihydrotestosterone. $n=6-8$ mice in each group. Values represent means \pm s.D. $* P<0.05$, $\star \star P<0.01$ compared with control. ${ }^{*} P<0.05$. (c) 2021 The authors Published by Bioscientifica Ltd

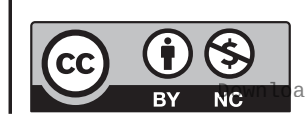

This work is licensed under a Creative Commons Attribution-NonCommercial 4.0 International License. ded from Bioscientifica.com at 04/26/2023 06:10:04AM via free access 
serum after TE exposure. It's worth noting that androgens excess, TE exposure was higher than its physiological level here, causes ER stress and insulin elevation in both insulinoma cell lines and islets, indicating this might be a kind of conserved response in $\beta$-cells that can be applied in other related studies. In addition, Azhary et al. demonstrated that androgen could activate ER stress in granulosa cells, and then enhance DR5 mediated apoptosis (1). Ours and others findings suggested that chronic androgen excess impairs the balance of ER protein folding process and cellular protein requirement and lead to accumulation of unfolded or misfolded insulin in ER, and then induces UPR response and apoptosis.

Bidirectional modulation of insulin homeostasis regulated by TE in male and females is one of the most sexually dimorphic aspects of metabolic control (35). In male, the deficiency of testosterone result in insulin resistance and T2DM. For example, testosterone therapy improves $\beta$ cell function and glycemic control in obese men who had secondary hypogonadism (36). In contrast, androgens excess predisposes women to insulin resistance and hyperglycemia. Female rats treated by androgens excess using DHEA show higher transcription of the insulin in pancreatic $\beta$ cells and hyperinsulinemia traits (37). Rat cell lines were used to dissect the effect of androgens excess on ER stress and hyperinsulinemia, this study is unable to encompass the entire aspects of in vivo experiments, which need to be further addressed in future studies. In the current study, we focused on the regulatory role of TE in female mice and found that TE exposure could significantly disrupt the insulin homeostasis in PCOS mice, which is consistent with the above bidirectional modulation of TE in male and female. Moreover, we found the detrimental effect of TE in female was mediated by the elevated ER stress and apoptosis in islets.

\section{Conclusion}

We demonstrated that TE exposure activates ER stress, induces apoptosis in $\beta$ cells, and disrupt insulin homeostasis in PCOS mice. Our findings suggest that ER stress activated by androgens excess in PCOS contributes to $\beta$ cell dysfunction and hyperinsulinemia.

\section{Declaration of interest}

The authors declare that there is no conflict of interest that could be perceived as prejudicing the impartiality of the research reported.

\section{Funding}

This work did not receive any specific grant from any funding agency in the public, commercial or not-for-profit sector.

\section{Acknowledgements}

The study was supported by the Basic Public Research Project of Zhejiang Province (LGF19H040014); the Natural Science Foundation of Zhejiang Province (LY16C120001)

\section{References}

1 Azhary JMK, Harada M, Takahashi N, Nose E, Kunitomi C, Koike H, Hirata T, Hirota Y, Koga K, Wada-Hiraike O, et al. Endoplasmic reticulum stress activated by androgen enhances apoptosis of granulosa cells via induction of death receptor 5 in PCOS. Endocrinology 2019160 119-132. (https://doi.org/10.1210/en.201800675)

2 Azziz R, Carmina E, Chen Z, Dunaif A, Laven JS, Legro RS, Lizneva D, Natterson-Horowtiz B, Teede HJ \& Yildiz BO. Polycystic ovary syndrome. Nature Reviews: Disease Primers 20162 16057. (https://doi. org/10.1038/nrdp.2016.57)

3 Escobar-Morreale HF. Polycystic ovary syndrome: definition, aetiology, diagnosis and treatment. Nature Reviews: Endocrinology 201814 270-284. (https://doi.org/10.1038/nrendo.2018.24)

4 Moran LJ, Hutchison SK, Norman RJ \& Teede HJ. Lifestyle changes in women with polycystic ovary syndrome. Cochrane Database of Systematic Reviews 20112 CD007506. (https://doi. org/10.1002/14651858.CD007506.pub3)

5 Glueck CJ \& Goldenberg N. Characteristics of obesity in polycystic ovary syndrome: etiology, treatment, and genetics. Metabolism: Clinical and Experimental 201992 108-120. (https://doi. org/10.1016/j.metabol.2018.11.002)

6 Kumarendran B, O'Reilly MW, Manolopoulos KN, Toulis KA, Gokhale KM, Sitch AJ, Wijeyaratne CN, Coomarasamy A, Arlt W \& Nirantharakumar K. Polycystic ovary syndrome, androgen excess, and the risk of nonalcoholic fatty liver disease in women: a longitudinal study based on a United Kingdom primary care database. PLoS Medicine 201815 e1002542. (https://doi.org/10.1371/ journal.pmed.1002542)

7 Dumesic DA, Oberfield SE, Stener-Victorin E, Marshall JC, Laven JS \& Legro RS. Scientific statement on the diagnostic criteria, epidemiology, pathophysiology, and molecular genetics of polycystic ovary syndrome. Endocrine Reviews 201536 487-525. (https://doi. org/10.1210/er.2015-1018)

8 Abbott DH, Dumesic DA \& Levine JE. Hyperandrogenic origins of polycystic ovary syndrome - implications for pathophysiology and therapy. Expert Review of Endocrinology and Metabolism 201914 131-143. (https://doi.org/10.1080/17446651.2019.1576522)

9 Walters KA, Rodriguez Paris V, Aflatounian A \& Handelsman DJ. Androgens and ovarian function: translation from basic discovery research to clinical impact. Journal of Endocrinology $20192 \mathbf{2 4 2}$ R23-R50. (https://doi.org/10.1530/JOE-19-0096)

10 Livadas S, Pappas C, Karachalios A, Marinakis E, Tolia N, Drakou M, Kaldrymides P, Panidis D \& Diamanti-Kandarakis E. Prevalence and impact of hyperandrogenemia in 1,218 women with polycystic ovary syndrome. Endocrine 201447 631-638. (https://doi.org/10.1007/ s12020-014-0200-7)

11 Hague WM, Adams J, Rodda C, Brook CG, de Bruyn R, Grant DB \& Jacobs HS. The prevalence of polycystic ovaries in patients with congenital adrenal hyperplasia and their close relatives. Clinical Endocrinology 199033 501-510. (https://doi. org/10.1111/j.1365-2265.1990.tb03887.x) 
12 Rittmaster RS. Antiandrogen treatment of polycystic ovary syndrome. Endocrinology and Metabolism Clinics of North America 1999 28 409-421. (https://doi.org/10.1016/s0889-8529(05)70077-3)

13 Ryan GE, Malik S \& Mellon PL. Antiandrogen treatment ameliorates reproductive and metabolic phenotypes in the letrozole-induced mouse model of PCOS. Endocrinology 2018159 1734-1747. (https:// doi.org/10.1210/en.2017-03218)

14 Silva MS, Prescott M \& Campbell RE. Ontogeny and reversal of brain circuit abnormalities in a preclinical model of PCOS. JCI Insight 2018 3 e99405. (https://doi.org/10.1172/jci.insight.99405)

15 Caldwell ASL, Edwards MC, Desai R, Jimenez M, Gilchrist RB, Handelsman DJ \& Walters KA. Neuroendocrine androgen action is a key extraovarian mediator in the development of polycystic ovary syndrome. PNAS 2017114 E3334-E3343. (https://doi.org/10.1073/ pnas.1616467114)

16 Walter P \& Ron D. The unfolded protein response: from stress pathway to homeostatic regulation. Science 2011334 1081-1086. (https://doi.org/10.1126/science.1209038)

17 Ron D \& Walter P. Signal integration in the endoplasmic reticulum unfolded protein response. Nature Reviews: Molecular Cell Biology 2007 8 519-529. (https://doi.org/10.1038/nrm2199)

18 Takahashi N, Harada M, Hirota Y, Nose E, Azhary JM, Koike H, Kunitomi C, Yoshino O, Izumi G, Hirata T, et al. Activation of endoplasmic reticulum stress in granulosa cells from patients with polycystic ovary syndrome contributes to ovarian fibrosis. Scientific Reports 20177 10824. (https://doi.org/10.1038/s41598-017-11252-7)

19 Eizirik DL \& Cnop M. ER stress in pancreatic beta cells: the thin red line between adaptation and failure. Science Signaling 20103 pe7. (https://doi.org/10.1126/scisignal.3110pe7)

20 Petremand J, Puyal J, Chatton JY, Duprez J, Allagnat F, Frias M, James RW, Waeber G, Jonas JC \& Widmann C. HDLs protect pancreatic beta-cells against ER stress by restoring protein folding and trafficking. Diabetes 201261 1100-1111. (https://doi. org/10.2337/db11-1221)

21 Cerf ME. Beta cell dysfunction and insulin resistance. Frontiers in Endocrinology 20134 37. (https://doi.org/10.3389/fendo.2013.00037)

22 Azhary JMK, Harada M, Kunitomi C, Kusamoto A, Takahashi N, Nose E, Oi N, Wada-Hiraike O, Urata Y, Hirata T, et al. Androgens increase accumulation of advanced glycation end products in granulosa cells by activating ER stress in PCOS. Endocrinology 2020 161 bqaa015. (https://doi.org/10.1210/endocr/bqaa015)

23 Cox MJ, Edwards MC, Rodriguez Paris V, Aflatounian A, Ledger WL, Gilchrist RB, Padmanabhan V, Handelsman DJ \& Walters KA Androgen action in adipose tissue and the brain are key mediators in the development of PCOS traits in a mouse model. Endocrinology 2020161 bqaa061. (https://doi.org/10.1210/endocr/bqaa061)

24 Kooptiwut S, Hanchang W, Semprasert N, Junking M, Limjindaporn T \& Yenchitsomanus PT. Testosterone reduces AGTR1 expression to prevent beta-cell and islet apoptosis from glucotoxicity. Journal of Endocrinology 2015224 215-224. (https://doi.org/10.1530/ JOE-14-0397)

25 Elouil H, Bensellam M, Guiot Y, Vander Mierde D, Pascal SM, Schuit FC \& Jonas JC. Acute nutrient regulation of the unfolded protein response and integrated stress response in cultured rat pancreatic islets. Diabetologia 200750 1442-1452. (https://doi. org/10.1007/s00125-007-0674-4)

26 Huang JS, Guo BB, Wang GH, Zeng LM, Hu YH, Wang T \& Wang HY. DGAT1 inhibitors protect pancreatic beta-cells from palmitic acidinduced apoptosis. Acta Pharmacologica Sinica 202142 264-271. (https://doi.org/10.1038/s41401-020-0482-7)

$27 \mathrm{Hu}$ H, Tian M, Ding C \& Yu S. The C/EBP homologous protein (CHOP) transcription factor functions in endoplasmic reticulum stress-induced apoptosis and microbial infection. Frontiers in Immunology 20189 3083. (https://doi.org/10.3389/ fimmu.2018.03083)

28 Handgraaf S \& Philippe J. The role of sexual hormones on the enteroinsular axis. Endocrine Reviews 201940 1152-1162. (https:// doi.org/10.1210/er.2019-00004)

29 Fonseca SG, Gromada J \& Urano F. Endoplasmic reticulum stress and pancreatic beta-cell death. Trends in Endocrinology and Metabolism 201122 266-274. (https://doi.org/10.1016/j.tem.2011.02.008)

30 Hotamisligil GS. Endoplasmic reticulum stress and the inflammatory basis of metabolic disease. Cell 2010140 900-917. (https://doi. org/10.1016/j.cell.2010.02.034)

31 Salvado L, Palomer X, Barroso E \& Vazquez-Carrera M. Targeting endoplasmic reticulum stress in insulin resistance. Trends in Endocrinology and Metabolism 201526 438-448. (https://doi. org/10.1016/j.tem.2015.05.007)

32 Kawasaki N, Asada R, Saito A, Kanemoto S \& Imaizumi K. Obesityinduced endoplasmic reticulum stress causes chronic inflammation in adipose tissue. Scientific Reports 20122 799. (https://doi. org/10.1038/srep00799)

33 Jiao P, Ma J, Feng B, Zhang H, Diehl JA, Chin YE, Yan W \& Xu H. FFA-induced adipocyte inflammation and insulin resistance: involvement of ER stress and IKK $\beta$ pathways. Obesity 201119 483-491. (https://doi.org/10.1038/oby.2010.200)

34 Bobrovnikova-Marjon E, Pytel D, Riese MJ, Vaites LP, Singh N, Koretzky GA, Witze ES \& Diehl JA. PERK utilizes intrinsic lipid kinase activity to generate phosphatidic acid, mediate Akt activation, and promote adipocyte differentiation. Molecular and Cellular Biology 201232 2268-2278. (https://doi.org/10.1128/ MCB.00063-12)

35 Schiffer L, Kempegowda P, Arlt W \& O'Reilly MW. Mechanisms in endocrinology: the sexually dimorphic role of androgens in human metabolic disease. European Journal of Endocrinology 2017177 R125-R143. (https://doi.org/10.1530/EJE-17-0124)

36 Dimitriadis GK, Randeva HS, Aftab S, Ali A, Hattersley JG, Pandey S, Grammatopoulos DK, Valsamakis G, Mastorakos G, Jones TH, et al. Metabolic phenotype of male obesity-related secondary hypogonadism pre-replacement and post-replacement therapy with intra-muscular testosterone undecanoate therapy. Endocrine 201860 175-184. (https://doi.org/10.1007/s12020-017-1516-x)

37 Mishra JS, More AS \& Kumar S. Elevated androgen levels induce hyperinsulinemia through increase in INS1 transcription in pancreatic beta cells in female rats. Biology of Reproduction 201898 520-531. (https://doi.org/10.1093/biolre/ioy017)

Received in final form 25 January 2021

Accepted 4 February 2021

Accepted Manuscript published online 6 February 2021 https://ec.bioscientifica.com https://doi.org/10.1530/EC-20-0608 (c) 2021 The authors Published by Bioscientifica Ltd

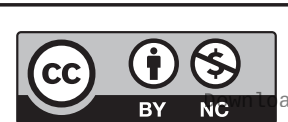

This work is licensed under a Creative Commons Attribution-NonCommercial 4.0 International License. ded from Bioscientifica,com at 04/26/2023 06:10;04AM 